\title{
As cartas no Anatômico jocoso (1755), de Frei Lucas de Santa
}

\section{Catarina}

\author{
The letters in Anatômico jocoso (1755), by Frei Lucas de Santa \\ Catarina
}

\author{
Valnikson Viana de Oliveira ${ }^{*}$ \\ valnikson18@hotmail.com \\ Universidade Federal da Paraíba
}

Socorro de Fátima Pacífico Barbosa ${ }^{*}$

socorrofpbarbosa@hotmail.com

Universidade Federal da Paraíba

RESUMO: O presente artigo tem como objetivo apresentar uma análise das missivas contidas no tomo II do periódico português Anatômico jocoso (1755), atribuído a Frei Lucas de Santa Catarina. Este trabalho também busca lançar luz sobre os modos de composição epistolar nos periódicos jocosos portugueses, em seu diálogo com a correspondência jornalística e periódica e com a prática cotidiana de urbanidade dos escritores de cartas (MIRANDA; LISBOA, 2011). Para tal, foi feito um levantamento dos principais temas contidos nas cartas, além da presença de composições em verso, revelando aspectos interessantes sobre algumas práticas de leitura e de escrita no século XVIII português. Ademais, considerando o que afirma D. F. Mckenzie (2004) sobre o fato de novos suportes criarem novos gêneros, este artigo também visa contribuir com os estudos da história da literatura e dos gêneros literários, particularmente no que tange à sua origem, à sua fusão ou ao seu desaparecimento, quando de sua publicação em suportes diversos. Como resultado, percebemos que o nosso corpus demonstra o papel da epístola como gênero literário e retórico proeminente, apresentando expressiva crítica a comportamentos sociais, além de trazer a própria sátira à retórica e à poética por meio do tratamento jocoso oferecido aos vários modelos de carta presentes nos manuais e secretários, revelando artimanhas de composição e adaptação ao suporte folheto.

PALAVRAS-CHAVE: Anatômico jocoso. Cartas. Século XVIII. Frei Lucas de Santa Catarina.

ABSTRACT: This article aims to present an analysis of missives contained in tome II of the Portuguese jocular periodical Anatômico jocoso (1755), attributed to Frei Lucas de Santa Catarina. This work also seeks to shed light on the modes of

\footnotetext{
* Mestre em Letras pela Universidade Federal da Paraíba (UFPB) e aluno de Doutorado no Programa de Pós-Graduação em Letras (PPGL) da mesma instituição, vinculado à área de Literatura, Teoria e Crítica.

** Doutora em Literatura Brasileira pela Universidade de São Paulo (USP). Professora titular da Universidade Federal da Paraíba (UFPB), vinculada ao Programa de Pós-Graduação em Letras (PPGL) da mesma instituição. Bolsista de produtividade e pesquisa do Conselho Nacional de Desenvolvimento Científico e Tecnológico (CNPq).
} 
epistolary composition in Portuguese jocular journals, in their dialogue with journalistic and periodic correspondence, and with the daily practice of letter writers' urbanity (MIRANDA, LISBOA, 2011). For such purpose, a survey of the main themes contained in the letters was conducted, as well as a rendering of the presence of compositions in verse, revealing interesting aspects about some practices of reading and writing in 18th century Portugal. In addition, taking into account what D. F. Mckenzie (2004) affirms regarding the fact that new media creates new genres, this article aims to contribute to the studies of the history of literature and literary genres, particularly with regards of their origin, their merger or their disappearance when published throughout various media. As a result, we realize that our corpus demonstrates the role of the epistle as a prominent literary and rhetorical genre, presenting significant criticism of social behavior and bringing their own satire on rhetoric and poetics through the jocular treatment offered to various models of letter in the manuals and secretaries, revealing tricks of composition and adaptation to the leaflet support.

KEYWORDS: Anatômico jocoso. Letters. 18th Century. Frei Lucas de Santa Catarina.

\section{Introdução - Anatômico jocoso nos quadros do Antigo Regime de Portugal}

Em meados do século XVIII, circularam pela corte portuguesa os folhetos jocosos, caracterizados pelo seu caráter "burlesco, satírico, erótico e jocoso" (RODRIGUES, 1983, p. 71). Entre os principais títulos encontram-se Pinto renascido, empenado e desempenado: primeiro voo (1732), de Tomás Pinto Brandão, Folheto de Ambas Lisboas (1730-1731) e a coletânea objeto desse artigo, Anatômico jocoso, atribuída a Frei Lucas de Santa Catarina ${ }^{1}$. Sobre essa coletânea, Inocêncio Francisco da Silva, no Dicionário bibliográfico português (1858), afirma:

Esta coleção saiu primeiro em dois volumes in $4^{\circ}$, dizendo-se coligida e publicada pelo Dr. Pantaleão d'Escarçai Ramos; a que o ajuntaram depois $3^{\circ}, 4^{\circ}$ e $5^{\circ}$ em nome Fr. Francisco Rey de Abreu Mata Zeferino, que se tem como pseudônimo de Fr. Lucas. [...] O que não tem dúvida é, que do $1^{\circ}$ tomo se fez segunda edição, copiosamente aumentada, e se não me engano, também vi reimpresso o segundo. As peças contidas nos cinco tomos pertencem a vários autores; porém grande parte delas é indubitavelmente de Fr. Lucas de Santa Catarina, pois como suas as tenho e vi todas coligidas e citadas em

\footnotetext{
${ }^{1}$ Segundo Rodrigues (1983), Frei Lucas de Santa Catarina nasceu em Lisboa, em 1660, filho de Pascoa de Mesa e de Manoel de Andrade Barreto, cantor da Capela Real. Professou a Ordem dos Pregadores, no Real Convento de Benfica, em 20 de abril de 1680. Há dúvidas se teria efetuado os seus estudos no Convento de Benfica, onde teria se dedicado ao estudo da História Eclesiástica e Secular. Da vasta bibliografia elencada por Inocêncio Francisco da Silva (1858), no Dicionário Bibliográfico Português, interessa as obras que podem ser catalogadas como não oficiais (Academia Real de História, da qual fazia parte) ou religiosas (o frei era dominicano). Nesse rol, além de Anatômico jocoso, tem-se o Parnaso jocoseiro, com 592 páginas não numeradas, que consta de farsas, loas, entremeses etc., sendo as principais: "Das regateiras e malsins", "Do exame das danças", "Dos bichos", "Dos Ofícios", "Jardim de Apolo", "O carro de Faetonte" e "O Polifemo".
} 
outros volumes manuscritos de miscelâneas daqueles tempos (SILVA, 1858, p. 203).

Segundo Rodrigues (1983, p. 95), os folhetos do Anatômico jocoso foram recolhidos e publicados em Lisboa entre 1775 e 1778, em um compêndio encadernado de edição completamente licenciada pela censura. Essa publicação de papeis alheios, em maioria anônimos, usa uma assinatura pseudónima: Padre Fr. Francisco de Abreu Mata Zeferino. Esta prática de ocultação do nome é frequente na obra de Frei Lucas, sobretudo nos seus escritos mais ousados (RODRIGUES, 1983). Tal ação se deve, muito provavelmente, ao fato de esta veia cômica bater de frente com a sua posição de cardeal da Igreja. A compilação dos folhetos apresenta três tomos, com o primeiro constando de obras diversas, o segundo de cartas e o terceiro de gêneros teatrais (loas, entremezes e comédias).

Figura 1: Frontispício do segundo tomo do compêndio de folhetos de Anatômico jocoso.

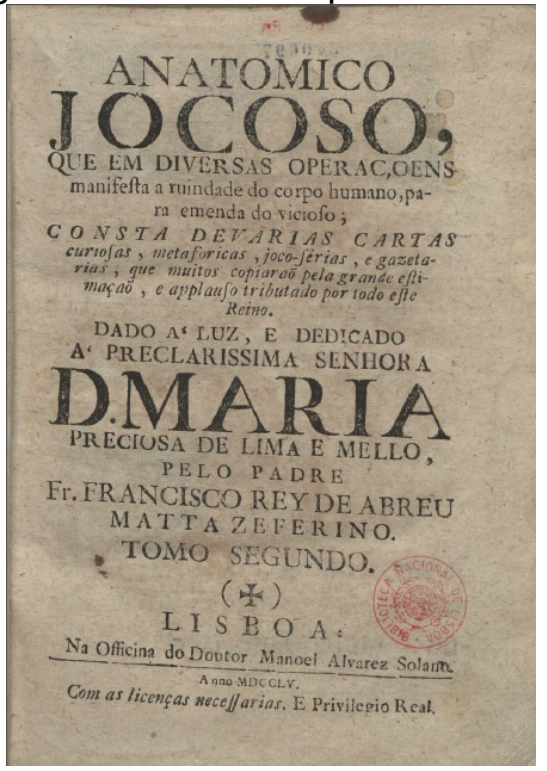

Fonte: Acervo digital da Biblioteca Nacional de Portugal.

Para esse artigo $^{2}$, foi considerado tão somente o segundo tomo, constituído por oitenta e três cartas ${ }^{3}$.

\footnotetext{
${ }^{2} \mathrm{O}$ presente estudo originou-se do Projeto de Iniciação Científica - PIBIC Ler e escrever nos folhetos periódicos lusos dos séculos XVIII e XIX, com plano de trabalho centrado na análise das cartas do periódico português Anatômico jocoso. A pesquisa foi premiada no XX Encontro Nacional de Iniciação Científica - ENIC, realizado em novembro de 2014, na Universidade Federal da Paraíba - UFPB, tendo o seu relatório final incluído em edição especial da série Iniciados, publicação em e-book da referida instituição com foco em trabalhos de destaque acadêmico.

${ }^{3}$ No decorrer da pesquisa, identificamos a presença de duas missivas além das oitenta e uma indicadas no INDEX da coleção. Uma é referenciada como anexo e a outra é simplesmente suprimida do guia apontado no início do tomo. Foi a partir disso que observamos uma possível relação
} 
É preciso, contudo, compreender alguns aspectos da carta, ou da correspondência, no quadro da cultura escrita do século XVIII, sobejamente no seu aspecto de noticiar, de exercer as funções próprias ao jornal. A principal delas tem origem na imprensa inglesa, no seu célebre periódico The Spectator, editado por Richard Steele e Joseph Addisson, que circulou entre março de 1711 e dezembro de 1712. Tal jornal inovou ao permitir que seus leitores escrevessem para a sua plataforma, além de seus editores usarem esse suporte para publicar ensaios, notícias etc.

O Anatômico jocoso é, portanto, a tradução do que Rocha (1985, p. 25) chama "de artificio que consiste em 'fingir' a forma epistolar" prática de todos os tempos, mas que se acentuou e "foi banalizada com o advento do jornalismo". Essa posição que defendemos vai de encontro à de Alfaro (1994, p. 11), que, em estudo dos mais importantes sobre a obra, toma as cartas como produtos reais e "autênticos" e não como objetos ficcionais: "O epíteto 'menor' é impróprio para os autores das cartas do Anatômico que seguramente, ao escreverem a uma freira ou a um amigo, não tinham em mente a edição com que a posteridade os havia de brindar" ${ }^{\prime \prime}$.

Contudo, devido ao sucesso dessa prática "na promoção de um ideal de sociabilidade polida", a correspondência de seus supostos leitores foi uma característica importante da publicação, com essas cartas podendo ou não, ocasionalmente, ser escritas pelos próprios editores (KUIPER, 2018, s/p.). Nesse

distribucional entre as cartas relacionadas a elementos da estrutura dos textos e a sua temática, 0 que pode ter motivado tal situação. A Carta XXI De piques, com rebuço de pêsames, por certa mudança, com resposta a ela (MATA ZEFERINO, 1755, p. 203-211) une duas missivas em seu interior. A carta Resposta (MATA ZEFERINO, 1755, p. 206-211) aparece anexada à carta que reponta, sendo assim indicada no INDEX. Contudo, notamos que a missiva que antecede este caso, a Carta XX Em que o Autor se desculpa com certas Religiosas de ter faltado, e acusa o que terão dele dito (MATA ZEFERINO, 1755, p. 194-202), também apresenta esta estrutura que compreende uma resposta ao texto primário. A carta traz, inicialmente, diversos comentários possivelmente proferidos por algumas freiras (referenciadas como flores), reclamando da ausência do autor da primeira carta, sendo respondidas logo depois com a justificação da falta. Com a leitura do texto, percebemos que estas falas foram na verdade possivelmente idealizadas pelo próprio autor desta, não constituindo realmente duas missivas, mas uma só dividida em duas partes: as possíveis reações das freiras em relação ao desaparecimento do autor e a resposta/justificativa deste a tais reações. Já a carta Ao mesmo Senhor Enviado (MATA ZEFERINO, 1755, p. 359-362) pode ter sido confundida com as duas outras que a antecedem, a Carta XXXXVII e a Carta XXXXVIII, já que as três apresentam o mesmo título. O organizador acabou por indicar no índice apenas duas dessas cartas homônimas.

${ }^{4}$ Essa opinião é parcialmente desconstruída na nota de rodapé $\mathrm{n}^{\circ} \mathrm{9}$, do capítulo II, na qual o autor afirma: "Com base na teoria que defendemos no Capítulo I deste trabalho (Cf. p. 37), julgamos poder atribuir a Frei Lucas grande parte das cartas que têm por tema a comida. No entanto, algumas das cartas freiráticas/antifreiráticas devem também ser do dominicano" (ALFARO, 1994, p. 153). 
sentido, também vale salientar que a epístola não deve ser confundida com uma carta comum:

[...] pois não se destina à simples comunicação de factos de natureza pessoal ou familiar, aproximando-se mais da crónica histórica que procura relatar acontecimentos do passado. A utilização do termo alarga-se, depois, a todo o tipo de correspondência privada ou oficial, literária ou filosófica, religiosa ou política [...] (CEIA, 2014, s/p.).

O segundo tomo de Anatômico jocoso consta de um Prólogo no qual se faz menção a uma quarta parte, apresentando mais gêneros teatrais, como entradas, farsas e comédias, e a uma quinta parte, apresentando obras poéticas. Tais volumes, infelizmente, não foram encontrados nos acervos históricos consultados. Em tal prefácio, o suposto organizador relata aos "curiosos leitores" que retirou as obras ali editadas de "duas gavetas velhas", de onde somente saiam para se "sacudirem do pó e o despertarem o riso, pérolas escondidas que o faziam companhia nas horas de tristeza há meia dúzia de anos", não se esquecendo de expor o seu propósito moral:

[...] me determinei a dar à luz estas crianças sem conhecidos pais, vendo com quanta diferença foram criadas, que com aquilo mesmo, que recreia os sentidos, vai repreendendo os costumes. [...] fui logo revolvendo as gavetas, sacando os cadernos, fazendo cinco Tomos de quarto, e todos volumosos, de que fiz cinco montes [...] e em todos eles, além do divertimento, terás com que enfeites as tuas Livrarias; com elas te poderás divertir, sem o escrúpulo de que em todas encontres coisa, que se opunha à pureza da Fé, nem à bondade dos costumes. Os maus muitas vezes os verás castigando com os ditos jocosos; mas por isto tem mais de graça, quanto mais castiga a culpa: a sua mesma variedade te fará mais saborosa à mesa; regala-te com ela, e por último pratinho me aceita a sempiterno Vale (MATA ZEFERINO, 1755, s/p).

O tom ficcional do relato do suposto organizador/prefaciador ressalta o teor ficcional do compêndio, que recolhe uma série de escritos em sua maioria sem assinatura, que podem ter sido fruto da sua própria criação. Trata-se de mais um artifício retórico da escrita em periódicos da época, entre as quais predomina a dissimulatio, que inclui o anonimato, o pseudônimo e os papéis encontrados ao acaso ou clandestinamente enviados ao(s) autor(es)/editor(es), todas estratégias de construção discursiva (BARBOSA, 2011).

\section{As múltiplas faces da carta nos periódicos jocosos}


O gênero epistolar tem sua importância pouco considerada por muitos historiadores que tendem a ler e a investigar os escritos literários do passado sem considerar suas apropriações e usos, bem como o momento histórico de sua publicação e os procedimentos de escrita próprios de cada gênero e suporte (MCKENZIE, 1999). Este artigo lança luz sobre práticas da escrita epistolar em periódicos jocosos portugueses do século XVIII. Voltamo-nos, mais especificamente, à prática escrita dos folhetos jocosos, cuja produção era bastante popular naquele tempo. Tal suporte, apagado da historiografia da imprensa e da literatura, possuindo raríssimas pesquisas a seu respeito (RODRIGUES, 1983; ALFARO, 1994; LISBOA, 2011; FERREIRA, 2018), aproximava-se dos periódicos "mais sérios" pela apropriação de gêneros noticiosos - como epístolas, relações, notícias, além de narrativas de caso e sonho - e gêneros retórico-poéticos - como máximas, epigramas, glosas, sonetos, apólogos, enigmas e adivinhações (BARBOSA, 2007).

Além de demonstrar o papel da epístola como gênero literário e retórico proeminente, até mesmo nos periódicos jocosos, este estudo demonstra a variedade de modelos que a carta assumia nos folhetos. É preciso, contudo, ressaltar a liberdade retórica que o estilo jocoso impunha às cartas, como já as caracterizava Rodrigues Lobo (1992):

As cartas jocosas, ou de galantaria, têm mais campo e liberdade para se poderem usar nelas alguns termos fora das limitações das nossas regras, porque, assim em se estenderem mais como em se sujeitarem menos, ficam desobrigadas das primeiras leis, que são brevidade sem enfeite, clareza sem rodeios, propriedade sem metáforas, pois o termo da graça e galantaria nisso se diferença do sisudo e pontual, não negando que há alguns que não perdem a graça nem o siso (LOBO, 1992, p. 101).

Assim, as cartas nos periódicos jocosos não fugiram à prática corrente de circulação e apropriação dos impressos, que consistia no processo de tradução e livre adaptação de todos os gêneros de escritos: "os periódicos não só traduziam livros completos, em excertos incluídos nas respectivas edições semanais ou mensais, mas também publicavam obras estrangeiras adaptadas de forma mais ou menos livre, por vezes sem qualquer referência ao autor" (FERREIRA, 2018, p. 239). Nesse artigo trabalhamos com a hipótese de que os folhetos jocosos no uso que fizeram da escrita epistolar são um dos elementos fundamentais para a mistura de alguns gêneros literários, tal como discute Pécora, na formulação dos gêneros que 
apresentam "formas mistas", no caso, em estudo com a fusão de gêneros eruditos com conteúdo jocoso (2001, p. 14)

Desde o século XIX que a carta deixou de frequentar a lista dos gêneros literários. Contudo, durante o século XVIII, a prática dessa escrita ia além do que supõe a concepção com que atualmente concebemos a escrita epistolar. Sua prática servia a vários propósitos, e estava inscrita nos procedimentos da retórica e seus usos que distinguiam a carta familiar daquela do homem da corte, o que leva à combinação de diversas tendências sobre a arte de escrever cartas, reveladas em inúmeros manuais, com modelos e tipos:

Mesmo do ponto de vista do simples cuidado com os aspectos de apresentação "externa" - como o tipo de traço, a inclinação ou a regularidade da letra -, aquilo que vale para um escrito mais propriamente "oficial" ou de "chancelaria" pode fazer-se presente na correspondência de cunho privado. $E$ à medida que se vai avançando no século XVII, a importância reconhecida ao justo domínio do "artificio", ou da "aparência" produz numerosos modelos de cartas "de secretários com os mais variados ornamentos, conceitos e figuras de ênfase" (LISBOA; MIRANDA, 2011, p. 371372).

Um número de Anatômico jocoso inteiramente dedicado às cartas representa bem a sátira a esse modismo que assolava a cultura escrita de Portugal, cuja prática foi disseminada por um variado número de manuais ou Secretários ${ }^{5}$, sendo o mais famoso deles o de Candido Lusitano (Francisco José Freire), O Secretário Português (1745), sem deixar de mencionar o mais antigo, Corte na aldeia (1619), de Rodrigues Lobo. É preciso esclarecer que a sátira à escrita epistolar é aqui tomada na acepção que lhe confere Hansen (2003, p. 69):

[...] a sátira não imita supostos "fatos" da empiria, mas encontra a realidade de seu tempo como sistema simbólico convencional de preceitos técnicos, verossimilhanças e decoros partilhados por sujeitos de enunciação, destinatários e públicos empíricos (HANSEN, 2003, p. 69).

Dessa forma, a prática da escrita epistolar envolvia desde assuntos, modelos, figuras, letras, a "gestos, hábitos e procedimentos" (LISBOA; MIRANDA, 2011, p.

\footnotetext{
${ }^{5}$ Lisboa e Miranda (2011, p. 373) listam alguns desses manuais: Perfeito pedagogo ou arte de educar a mocidade, em que se dão as regras da polícia e urbanidade cristã, conforme os costumes de Portugal (1782), de João Rosado de Vila Lobos; Escola política do tratado prático da civilidade portuguesa (1786), de D. João de Nossa S. da Porta Siqueira; Elementos da civilidade e da decência, para instrução da mocidade de ambos os sexos (1777), sem alusão a autor.
} 
373) e, por isso, nas cartas jocosas de o Anatômico, o "alvo principal da sua vituperação são ações que, por ameaçar e destruir a coesão pressuposta no conceito de "bem comum", são constituídas como abusos contra naturam, vício moral, erro político, heresia religiosa, que corrompem os bons usos estabelecidos" (HANSEN, 2003, p. 71).

Não é à toa que, entre as oito dezenas de cartas, encontram-se quase todos os tipos de cartas e de sujeitos representados nos modelos dos secretários, em sua forma jocosa, já identificada nos títulos. Assim, temos a Carta $\vee$ Que um amigo escreveu a outro dando-Ihe conta das maravilhosas causas, e razões extraordinárias, que precederam para chegar a seu poder a mais alta, e mui endeusada Genealogia da Senhora Maria da Gloria (MATA ZEFERINO, 1755, p. 6688), a Carta VII Do Autor dando desenganos a um freirático, e explicando que cousa é o amor (MATA ZEFERINO, 1755, p. 101-105), a Carta XII Em resposta de outra vinda do Brasil a esta Corte (MATA ZEFERINO, 1755, p. 150-158), Carta XXI De piques, com rebuço de pêsames, por certas mudanças, com resposta a ela (MATA ZEFERINO, 1755, p. 203-210), Carta LXXVIII Ou discurso do autor sobre as impaciências de Cloris em as fortunas de Nize (MATA ZEFERINO, 1755, p. 460468), entre outras.

Sem ser necessária a leitura das cartas em si, observa-se que, desde o índice, o Anatômico jocoso trata de forma jocosa os vários modelos de cartas, presentes nos manuais e secretários, resumindo-os a três tipos: metafóricas, jocosérias e gazetárias. É dessa forma que o segundo tomo de Anatômico jocoso apresenta algumas cartas que são traduções livres de obras consagradas. Por exemplo, a "Novela disparatória do gigante sonhado: obra joco-séria para divertimento de curiosos", de autoria de Antônio Serrão de Castro, publicada em 1745, pela oficina de Pedro Ferreira ${ }^{6}$, é apropriada e apresentada em forma de relato, na Carta IX Em que o Autor dá noticia a um amigo da Novela disparatória por ele composta a rogo de um Cavalheiro, que pediu-lhe a compusesse (MATA ZEFERINO, 1755, p. 113-133), demonstrando as artimanhas de composição no suporte folheto, ao mesmo tempo em que apresenta a ampla capacidade de adaptação e transformação do gênero epistolar e a sua representação social. Dessa

\footnotetext{
${ }^{6}$ Segundo Gomes (1981), a "Novela disparatória do gigante sonhado" circulou em Lisboa no século XVII, em forma manuscrita, e no século XVIII, em forma impressa, mas sem identificação do autor, fato ocorrido também com sua produção poética.
} 
forma, a nova versão traz modificações linguísticas (como quando se substitui o verso "Só para que me aquente" por "Só por ser amante quente") e de conteúdo, como a inserção de novos versos cantados pelo gigante do título e a nomeação de personagens anônimos (João Redondo, Maria das Flores, Taralhão, Galhano, Luiz Cordeiro, Sumecê, Perdoa ao Meco, Arado, Manoel Balão, Catimbão e Tiroliro). A novela, assim, ganhou transformações para melhor se adaptar ao folheto jocoso e a seu propósito de entreter os curiosos: "[...] como se conformaria bem um assunto joco-sério com um estilo grave, sem que o conceito, a hipérbole, e a metáfora the dessem aquela galantaria, e aquele pico, de que necessitam semelhantes discursos?" (MATA ZEFERINO, 1755, s/p).

É importante observar, ainda no prólogo ao leitor, que o estilo jocoso, por si só, já faz uma sátira à retórica e à poética, ressaltando sua falta de propósito:

Não tem havido remendão do Parnazo, nem bicho da cozinha da Retórica, que não vomite todos os dias toda quanta imundice a acharam nas alcovinhas daqueles bestuntos, e quanta porcaria encontraram nos caqueiros daqueles cérebros (MATA ZEFERINO, $1755, \mathrm{~s} / \mathrm{p})$.

O trecho refere-se ao conteúdo duvidoso dos folhetos, tidos pelo prefaciador como "malditos papelinhos que só serviam para traques", constituindo, a seu ver, "monstruosidades". Ele afirma que foram raros os que não fossem "frioleira", os quais acabou trazendo à luz da publicação quando se viu "magoado das injúrias, que se faziam a Portugal, tendo um Varão de tanto respeito". No caso dos folhetos, o humor jocoso claramente cumpria a função de repreender costumes daquele tempo, que permaneciam por meio de sua variedade, fazendo-o, através da "monstruosidade" de misturar estilos, tipos e assuntos das cartas, tão didaticamente separadas pelos manuais epistolares do tempo.

Percebemos também que muitas das cartas apresentavam gêneros poéticos em excerto ou completos, no corpo do texto ou em anexo, favorecendo o que viria a ser o hibridismo de gêneros, o nascimento de uns e a morte de outros (PÉCORA, 2001), cuja segmentação se dará no século XIX, com os românticos. Algumas dessas composições em verso constituem apropriação da obra de grandes escritores, conforme já assinalamos, seja por citação, paráfrase ou paródia. A incorporação de outros escritos em língua portuguesa ou castelhana é algo bem comum dentro das missivas estudadas. Seguem-se vários provérbios latinos, pequenas orações, trechos de poesia etc. Há também várias alusões a personagens 
da mitologia greco-romana e a grandes escritores da literatura clássica, como Homero, Virgílio, D. Antonio de Mendonça, Félix Lope de Vega, Luís Vaz de Camões, Pablo Gonçalves de Andrade e Luis de Góngora y Argote, aparentemente servindo para endossar o caráter pretensamente erudito do autor dos escritos jocosos, como no exemplo a seguir:

Nunca Páris experimentará tão cruel fortuna, se não preservará na ofensa do roubo de Helena; nem Sapho fora rendida das ondas, se na traição q cometeu, não permanece algum tempo. Diz Homero, com Virgílio, que a ousadia e ajudada da boa fortuna; mas eu acho, que pela maior parte e companheira de maior ruina: porque aquele, que sem fundamento ousado se manifesta, nasce da sua confiança, e leva esculpida a tragédia da sua ruina (MATA ZEFERINO, 1755, p. 467).

Todavia, ainda verificamos a interessante inserção de gêneros poéticos possivelmente escritos pelo(s) próprio(s) autor(es) das missivas em doze das oitenta e três cartas, monstruosidades do ponto de vista da poética. Assim, o levantamento da autoria desses excertos se deu por meio de um estudo aprofundado de todos os que são publicados em verso, contidos nas cartas. Verificamos que todos os gêneros poéticos de autoria reconhecida, geralmente mencionada no interior das cartas, aparecem em excertos, como no caso da citação a versos de Camões na Carta LVIII Descrevendo uma função festiva no Convento de Chelas:

[...] Consultemos a Camões neste caso, e recopilemos o fogo no Comento.

Não faltam ali raios de artifício, Os trêmulos cometas imitando, Fazem os fogueteiros seu ofício Todo o vale de Chelas atroando: Mostra-se dos marotos o exercício Os montinhos de pólvora queimado; Os sinos atilados 0 ar seriam, $E$ as laivosas lacaias os tangiam (MATA ZEFERINO, 1755, p. 390).

Já os gêneros poéticos cuja autoria seria de Fr. Francisco Mata Zeferino/Fr. Lucas de Santa Catarina, ao contrário dos que citam autores famosos, são apresentados em totalidade e não em trechos. Apenas a composição em verso contida na já citada Carta IX, atribuída a Antônio Serrão de Castro, é mostrada em totalidade, compondo o relato sobre a "novela disparatória do gigante sonhado". Identificamos que os "supostos" autores das cartas fazem uso de sonetos, quadras, 
décimas e epigramas, com os dois primeiros gêneros aparecendo com maior frequência dentro das cartas em relação aos outros. A utilização destes gêneros menores e mais populares pode ter se dado pela sua fácil memorização e cópia. $A$ Carta X Em que o Autor dá conta do sonho e triunfo de Amor ressuscitado, por exemplo, é antecipada por quadras, em redondilhas maiores que se espalham por toda a composição, intercalando a narração:

[...] Que assim havia de ser, para que fosse de todos os quatro costados tolo: ia esfriando o auditório, ele a soalheira do pandeiro dizia a letra:

E alegria, e alegria,

Ora viva de amor a companhia,

E todas elas eram boas,

Mas esta festa é melhor que todas.

Seguia-se finalmente Rei Davi o Alvoroço, faltando entres sustos, e bailando sobressaltos com uma alma e uns pés de mequetrefe; sobre a gala do aplauso, levava a mascarilha do silêncio (MATA ZEFERINO, 1755, p. 144).

O soneto é uma composição poética formada por quatorze versos distribuídos em duas quadras e dois tercetos, com utilização predominante do decassílabo (MOISÉS, 1974). As cartas do tomo II de Anatômico jocoso apresentam diversos sonetos que fundem os dois tipos de decassílabo indicados por Goldstein (2006, p. 39): o heroico, com ascendência rítmica na sexta e décima sílabas, e o sáfico, com ascendência na quarta, oitava e décima sílabas poéticas. Estes gêneros poéticos aparecem geralmente no final das epístolas ou mesmo como anexo, concretizando um tom de despedida. A maioria representa uma síntese do que foi tratado pelo(s) autor(es) na carta. O soneto no final da Carta XV Que o Autor escreveu a irmão, e pai, e desenganado (MATA ZEFERINO, 1755, p. 169-171) é enviado de presente ao irmão do(s) autor(es) que acaba de se tornar pai. $O(s)$ tio(s) da criança decide(m) retratar as boas novas na carta em verso e apresentar sua faceta artística ao parente:

\footnotetext{
Pariu vossa mulher em terça feira

Tantos de Março, enfim, porque em rigor

Para assistir ao parto de uma flor

Somente o Março pode ser parteira.

Na semana de Ramos lisonjeira

Inspirou a fortuna em seu favor;

Porque em tempos de palmas quis dispor

Que fosses Palmeirim, e ela Palmeira.

Oh grande mês sempre à memoria eterno!

Pois em ti (se hoje sábio o considera

$\mathrm{O}$ assombro a que presado de sisudo)
} 


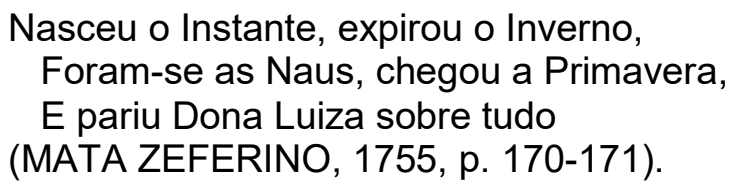

Algo interessante a se notar é que o jogo de palavras feito pelo(s) eu-lírico(s) contribui para um maior entendimento da missiva a partir do soneto. É utilizado, no último verso da segunda estrofe, o termo "Palmeirim", que significa peregrino, forasteiro ou estrangeiro, para se referir ao irmão. Até a leitura da poesia, só poderíamos inferir que o destinatário estava distante da família. O verso traz uma possível informação que justifica esta ausência: a figura paterna pode pertencer a alguma estância nômade de trabalho. O uso da palavra "Palmeira" para designar a cunhada Dona Luiza reforça a construção do(s) autor(es) em lamentar pela separação familiar, com a mulher presa, enraizada ao seu lar enquanto o companheiro se encontra distante. Além disso, em toda a construção do gênero poético há demarcações do tempo, com a criança nascendo numa terça-feira da "semana de Ramos" no mês de março, trazendo a primavera e acabando com o inverno. Podemos interpretar que se faz referência de certo modo à longevidade do período em que o irmão se encontra fora de casa, com a necessidade de mostrar as datas determinadas.

Além dessa contribuição para a compreensão completa da carta, muitos gêneros poéticos também são usados como artifício próprio da sátira pretendida pelo(s) autor(es). A décima é um gênero de estrofe única com dez versos. Moisés (1974, p. 115) a divide em dois tipos: a décima medieval, muito popular no século $\mathrm{XVI}$, e a décima clássica ou "espinela" (em homenagem ao seu presumido inventor, o poeta espanhol do século XVI, Vicente Espinel), formada por uma quadra e uma sextilha heptassilábicas obedecendo, majoritariamente, ao esquema de rimas abbaaccddc. O(s) autor(es) da Carta LV Em que se agradecem umas empadas de rolas. (MATA ZEFERINO, 1755, p. 384), assim como o(s) da Carta LVI Agradecendo umas empadas de Lampreia. (MATA ZEFERINO, 1755, p. 385-386), faz(em) uso da décima clássica para agradecer empadas recebidas de amigos, como que realizando uma troca de favores. Os gêneros poéticos são anexados às missivas como verdadeiras encomendas. A sátira se faz clara especialmente nas décimas da Carta LVI, dedicadas "A uma Lampreia recolhida em empadinhas". 
No que se refere a outro gênero poético: o epigrama, cuja temática é centrada em pensamentos ligados à tristeza e ao luto, podendo ser formado por mais de uma estrofe, mas raramente tendendo a estender-se muito (MOISÉS, 1974), também é possível identificá-lo nas composições. A Carta XXXIX De despique do amante Lauso Tolo, chamando-Ihe a sua Dama Tolo é finalizada por um epigrama que volta a realçar a tolice de quem a redige:
Assim anda o mundo à roda,
Lauso, se noto advertido
Que ontem foi entendido
E hoje a Tolo se acomoda,
Saiba-se de polo a polo
Vossa mudança, Senhor;
Pois de Tântalo de Amor
Sois hoje de Amor tão Tolo
(MATA ZEFERINO, 1755, p. 321).

O "Lauso Tolo" é comparado à figura mitológica de Tântalo, referida popularmente como aquele que deseja algo aparentemente próximo, porém inalcançável, sofrendo por isso.

Ao contrário dos outros gêneros poéticos, a quadra aparece com maior frequência dentro do corpo do texto, e não no final. Também chamada de "quadrinha" ou "trova", constitui uma única estrofe de quatro versos que se autonomizou como gênero, se tornando muito presente na literatura popular com temática bem abrangente (MOISÉS, 1974). É composta, especialmente, por versos heptassílabos. A Carta XXXIII Carta mandadeira, que se mandou por entrudo a certo Convento em nomes dos Noviços de outro (MATA ZEFERINO, 1755, p. 258-268) apresenta uma interessante série composta por dezenove quadrinhas simbolizando diversos alimentos enviados como presente a freiras de um convento:

Este papel leva o presente.

O presente abreviado

Vai, sem que se lhe dê disso,

Sem doces em papeliço,

Sem momos empapelado.

FRANGAS.

Essas quatro franguinhas

Desta casa vão sem falha;

E é que daqui da Batalha

Fogem como são galinhas.

COELHOS. 
Este vai por meu conselho, Que mostrar-Ihe a vocês trata, Que esta nossa casa é mata, De que pode vir coelho.

[...] (MATA ZEFERINO, 1755, p. 262-263).

$\mathrm{O}(\mathrm{s})$ autor(es) da missiva, identificado(s) apenas como noviços de outro convento, a assinam com pseudônimos e justificam as prendas observando que as religiosas comem mais com os olhos que com a boca, preferindo assim enviá-las "onde tudo se pode ler, e nada se chega a mastigar; porque assim ficarão em jejum os beiços, mas mui fartos os olhos" (MATA ZEFERINO, 1755, p. 260). A lista extensa de iguarias acentua a sátira à gula das freiras ao mesmo tempo em que brinca com o amor freirático construído pela conveniência.

O tomo II do Anatômico jocoso, objeto de nossa análise, é constituído por cartas descritas no Index como curiosas, joco-sérias, metafóricas e gazetárias. É importante observar que, na denominação dessas cartas, o compêndio já está fugindo às regras e à tipologia dos manuais de escrever cartas próprias ao seu tempo. Por exemplo, o já referido Secretário português, ou método de escrever cartas já previa o gênero misto de cartas, que consistia em dois tipos: as discursivas e as satíricas ou de desprezo (FREIRE, 1801):

[...] a carta satírica consiste na persuasão Ética; porque o objeto da sátira são os vícios, e então não é mais que uma repreensão deles: confesso que há de ser mordaz, porem saiba também v. m. que deve ser encoberta com tanta dissimulação, como engenho; porque é detestável toda a mordacidade patente, e despida de agudeza". [...] De modo que a sátira não difere da acusação na substancia, senão no estilo, e por este fundamento se reduz a contextura de tais Cartas a estes dois pontos que são narração das ações viciosas dissimuladamente manifestas, e reflexões mordazes e simuladamente manifestas, e reflexões mordazes, e agudas por meio de equívocos, apotegma ${ }^{7}$ e expressões irônicas, que lisonjeando repreenderão (FREIRE, 1801, p. 269-270).

\footnotetext{
${ }^{7}$ Frase breve de carácter aforístico, geralmente de alcance universal. $\mathrm{O}$ apotegma aparece quase sempre com linguagem figurativa e na forma de uma máxima ou sentença. Distingue-se do aforismo e do provérbio por ser mais prático e focalizado; a autoria do apotegma é também, regra geral, reservada a figuras notáveis da cultura, ao passo que o aforismo e o provérbio podem ter origem popular. [...] O Padre Manuel Bernardes deixou na sua A Nova Floresta ou Silva de Vários Apotegmas, e Ditos Sentenciosos Espirituais, e Morais, com Reflexões em que o Útil da Doutrina se Acompanha com o Vário da Erudição Assim Divina, Como Humana (5 vols., 1706-1728) uma importante colecção de apotegmas. O Marquês de Maricá ficou célebre pelas suas Máximas, Pensamentos e Reflexões (1837-43), de onde se regista este apotegma: "A vaidade de muita ciência é prova de pouco saber." (CEIA, 2018).
} 
Com a catalogação, pudemos perceber que o critério organizacional adotado pelo antologista Fr. Francisco de Abreu Mata Zeferino (na verdade Fr. Lucas de Santa Catarina) não corresponde a nenhuma ordem clara de viés temporal ou autoral. A seleção das epístolas pode ter sido influenciada por diversos fatores, tais como a curiosidade individual do organizador, a atenção com o público leitor, uma ordem censória exterior, o grau de jocosidade, seu efeito didático e moral etc. Todavia, acreditamos que a disposição das cartas possivelmente foi guiada pela temática ou por elementos estruturais parecidos. Ademais, é interessante lembrar que a reunião/apropriação dos folhetos não pode ser vista como parte de procedimentos editoriais de falsificação, tal como é conhecida e combatida em nossos dias. Trata-se, segundo Chartier (2012), de uma prática que integrava o universo da leitura e da palavra impressa da época, sem que isso fosse considerado crime, visto que ainda não existia a noção de propriedade autoral dos escritores, com o direito de publicação permanecendo nas mãos de editores, livreiros e impressores. Para além do seu "valor literário", os folhetos interessam aos estudiosos da leitura e da cultura escrita, pois revelam a passagem do mecenato para o "novo regime literário", no qual o autor vendia e vivia do que escrevia.

Figura 2: Primeiras páginas do Index do segundo tomo do compêndio de folhetos de Anatômico jocoso.

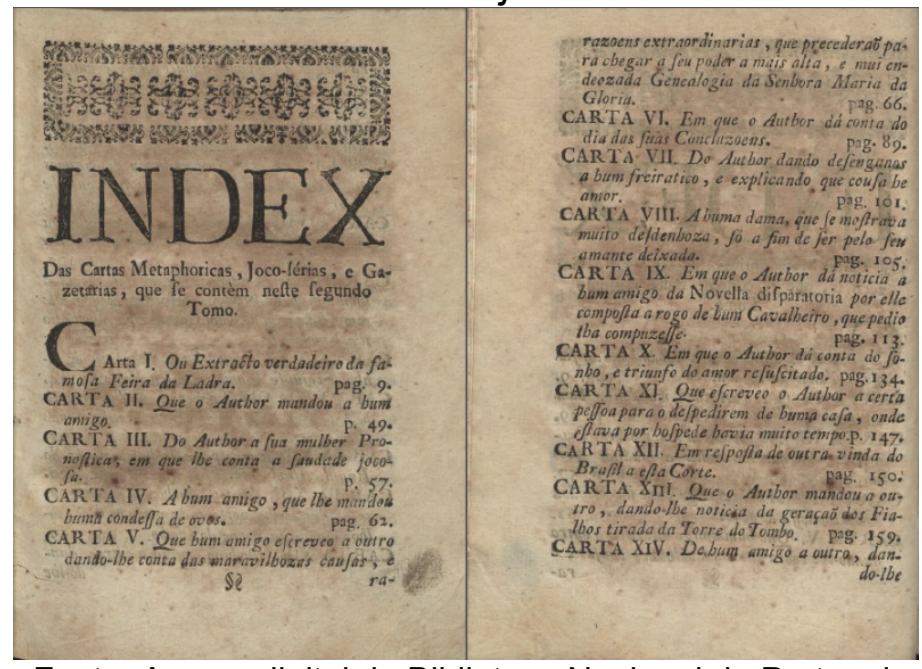

Fonte: Acervo digital da Biblioteca Nacional de Portugal.

Em linhas gerais, em relação à autoria das cartas, prevalece o anonimato (com exceção do caso flagrante do mencionado Antônio Serrão de Castro), prática comum que se estenderia até o século XIX. Algumas das missivas, como vimos, vinculam-se a pseudônimos ou nomes alegóricos relacionados ao assunto nelas 
tratado. O que chama a atenção é a prática de escrita recorrente e extensiva também aos periódicos regulares que costumam incluir leitores e escritores forjados pelo próprio editor do jornal. Faz-se notável, por exemplo, a gama de figuras clericais apontadas (ou criadas) como autoras das cartas. É o caso dos personagens cardeais que supostamente teriam escrito a mencionada Carta XXXIII, identificados da seguinte maneira:

Frei Eu. Frei Frade. Frei Irmão. Frei Desejo da Incarnação. Frei Umbigo das Saldades. Frei Aquele Daquilo. Frei Não sei que. Frei O que vocês quiserem. Frei Bugalho do Dezerte. Apelem mais vocês. Frei Nada. Frei Chafariz de Água suja. Frei Desejo de Bem sei que. Frei Aquilo de Carvalho. Frei Coisa nenhuma. Frei Isso. Frei Cuco. Frei Caco. Frei Beco (Este é a cortesia.) Frei Que esqueceu. Frei Último. Frei Basta (MATA ZEFERINO, 1755, p. 262).

Tais pseudônimos, ressaltados como estratégia retórica de dissimulatio, afirmam o tom jocoso da missiva, jogando com a importância do cargo religioso, misturando-o a expressões populares e de duplo sentido, ao mesmo tempo em que brincam com a estrutura séria do gênero, visto que aparecem em uma seção formal de assinatura ao final da carta.

Para Costa (2007, p. 126), por outro lado, este anonimato presente nas cartas é vinculado, muito provavelmente, a questões de censura, que também afetam diretamente o seu conteúdo e o seu sentido. Algo importante, nesse conjunto de cartas, diz respeito a presença em duas delas, desse caráter "metalinguístico" - sem querer ser anacrônico - acerca, exatamente do controle imposto à leitura. A Carta $L$ Escrita a um amigo (MATA ZEFERINO, 1755, p. 365-368) apresenta justificativas do possível autor para a censura de um livro posto por ele à publicação, enquanto a Carta LI A um amigo dando-Ihe esta notícia (MATA ZEFERINO, 1755, p. 369-374) traz o discurso censor do autor em relação à possível deturpação do sistema religioso e político de Portugal, por um estudante que faz uso de livros proibidos. Alguns indivíduos conseguiam permissões especiais para ler obras banidas, fugindo da ilegalidade. No entanto, isso dificultava ainda mais o controle do governo sobre a circulação destes livros censurados, que acabavam também sendo adquiridos por alguns "desautorizados" (VILLALTA, 2006). Esta situação é mostrada intimamente na referida Carta LI, que é possivelmente dirigida a alguma autoridade jurídica vinculada à censura.

Em relação à tipologia do padrão de escrita das missivas, retomamos o manual epistolar de Freire (1801), que as divide entre os três gêneros do discurso 
retórico: o demonstrativo, com cartas de parabéns, oferecimento, agradecimento, aviso, discursivas e de louvor; o judicial, com cartas de desculpa ou justificação e queixa; e o deliberativo, com cartas de pêsames, recomendação, boas festas, consolação, exortação e conselho. O primeiro, também chamado de epidícto, se relaciona a considerações de louvor e de censura; o segundo, às funções de acusação e de defesa; e o terceiro, às atividades de aconselhar e de desaconselhar pela persuasão (LAUSBERG, 1967).

Como pudemos notar, a maioria dessas cartas analisadas funciona como uma espécie de "crônica" contaminada por sátira aos vícios, costumes e comportamentos públicos ou privados de figuras estereotipadas da sociedade do século XVIII português. Observamos que os temas mais recorrentes nas cartas são o amor freirático e a gula, com alguns escritos ligados à clausura dos conventos e dos mosteiros, além do comportamento das mulheres.

O amor freirático foi um tópico muito explorado por diversos escritores setecentistas. Segundo Hansen (2003, p. 79), o assunto envolve a relação das freiras com os mais diversos homens que tinham acesso ao claustro, como padres, frades, vigários, músicos, arquitetos, parentes e outros afidalgados, caracterizados ridiculamente como presunçosos e tolos. Este amor "não natural" faz embate com a missão espiritual das noviças e aparece mais como desenganado ou refratado do que como celebrado, sendo preceito para o humor. As missivas ressaltam as frustrações de se manter uma relação encerrada sob as grades do convento. São colocados na posição de Autor o próprio freirático ou algum amigo seu que comenta sobre o caso amoroso.

As cartas sobre a gula são dominadas por muitas notas de agradecimento a presentes ou a trocas comerciais. Notamos uma sátira acentuada à gula como vício dos religiosos. Muitos deles permutavam versos e outros escritos literários, os chamados "equívocos", por alimentos de seu gosto, como uma botelha de vinho, empadas, alface, presunto, etc. As missivas se tornam verdadeiros documentos sobre as ligações entre o sagrado e profano através da sátira aos hábitos e costumes dos membros da Igreja.

A representação da mulher encontrada nas cartas vai ao encontro do papel social do século XVIII, em que nasciam para serem boas filhas, esposas e mães, sendo submissas durante toda a vida. As damas que fugissem desta natureza inferior e limitada em relação ao homem eram duramente criticadas. Ademais, 
segundo Hansen (1989, p. 331), a partição fundamental da sátira é na verdade a de "pecado/não pecado", que se estende a todos os corpos, tanto do sexo feminino como do masculino. A já referida Carta XXXIX De despique do amante Lauso Tolo, chamando-Ihe a sua Dama Tolo (MATA ZEFERINO, 1755, p. 289-321) é um extenso relato sobre o adultério. A Dama referenciada, chamada de Amarilis, tem o caso amoroso secreto exposto pelo próprio amante em um ato de vingança por esta tê-lo desprezado. Acontece que a carta também apresenta sátira à ação do homem pecador retratando-o como um bobo desiludido, o "Lauso Tolo". Temos que, mesmo com a recorrência de alvo a algumas figuras determinadas, como a mulher e o freirático, a sátira feita nas cartas se estende aos comportamentos estereotipados dentro da sociedade portuguesa.

\section{Conclusão}

$O$ ato de escrever cartas é um costume antigo, assim como a sua compilação e a atração que exerce sobre os leitores. Vemos que o termo "anatômico", derivado de "anatomia", o ramo da biologia que estuda a estrutura e a forma dos elementos constituintes do corpo humano, resume bem a premissa do periódico aqui estudado. Unido ao vocábulo "jocoso", a palavra traz à tona uma verdadeira dissecação, quiçá uma autópsia da sociedade portuguesa do seu tempo através de textos de natureza variada, mas sempre ligados pela sátira mordaz aos costumes e atitudes dos tipos estereotipados (RODRIGUES, 1983).

Excluídos dos manuais de história da literatura, esses folhetos jocosos são determinantes na compreensão das "monstruosidades" retórico-poéticas, que culminaram com a ruptura total dos gêneros literários e poéticos no século seguinte. O fato de as cartas atribuídas a Frei Lucas de Santa Catarina revelar construções textuais alheias aos manuais e secretários demonstram a sua importância no processo da escrita literária e ficcional. Elas se constituem como um espaço de comunicação e valem como criação literária com forte veia satírica de viés doutrinário, mesmo que tal intenção pedagógica e moralista seja veiculada por meio de uma lúcida e divertida sátira, sobretudo a componentes da Igreja, que profanam sua missão espiritual através de pecados.

\section{REFERÊNCIAS}


ALFARO, J. O jogo das cartas. O lúdico numa antologia epistolar barroca. Lisboa: Quimera, 1994.

BARBOSA, S. F. P. A escrita epistolar como prosa de ficção: as cartas do jornalista Miguel Lopes do Sacramento Gama. Revista Desenredo. v. 7, n. 2, 2011. p. 331344. Disponível em: http://seer.upf.br/index.php/rd/article/view/2406. Acesso em: 6 ago. 2019.

BARBOSA, S. F. P. Jornal e literatura: a imprensa brasileira no século XIX. Porto Alegre: Ed. Nova Prova, 2007.

CEIA, C. E-Dicionário de termos literários. 2014. Disponível em: http://edtl.fcsh.unl. pt/encyclopedia/apotegma/. Acesso em: 6 ago. 2019.

CHARTIER, R. Cardenio entre Cervantes e Shakespeare: história de uma peça perdida. Trad. Edmir Missio. Rio de Janeiro: Civilização Brasileira, 2012.

COSTA, A. C. M. Erudição e utilitas na obra de Frei Lucas de Santa Catarina. Porto: Ed. do autor, 2007.

FERREIRA, J. P. R. Castigar a rir. O humor na imprensa periódica em Portugal (1797-1835). Lisboa: Universidade Nova de Lisboa, 2018. Tese de Doutorado. Disponível em: http://hdl.handle.net/10362/43440. Acesso em: 02 abr. 2019.

FREIRE, F. J. Secretario português ou método de escrever cartas. Lisboa: Tipografia Rolandiana, 1801.

GOMES, M. J. Os ratos da inquisição - do judeu português Antônio Serrão de Castro, prefaciado por Camillo Castello Branco. Lisboa: Contexto, 1981.

GOLDSTEIN, N. S. Versos, sons, ritmos. São Paulo: Ática, 2006.

HANSEN, J. A. Pedra e cal: freiráticos na sátira luso-brasileira do século XVII. In: Revista USP. n. 57, 2003. p. 68-85. Disponível em: https://www.revistas.usp.br/ revusp/article/download/33834/36567. Acesso em: 6 ago. 2019.

HANSEN, J. A. Os lugares do lugar. In: HANSEN, J. A. A sátira e o engenho: Gregório de Matos e a Bahia do século XVII. São Paulo: Companhia das Letras, Secretaria de Estado da Cultura, 1989. p. 305-393.

KUIPER, A. The Spectator: british periodical [1711-1712]. In: Encyclopaedia britannica. Disponível em: https://www.britannica.com/topic/the-spectator-britishperiodical -1711-1712. Acesso em: 6 ago. 2019.

LAUSBERG, H. Elementos de retórica literária. Lisboa: Fundação Calouste Gulbenkian, 1967.

LISBOA, J. L. O Anatômico entre os papeis jocosos setecentistas. In: LUSTOSA, I. (Org.). Imprensa, humor e caricatura: a questão dos estereótipos culturais. Belo Horizonte: EdUFMG, 2011. p. 392-405. 
LISBOA, J. L. MIRANDA, T. C. P. dos Reis. A cultura escrita nos espaços privados. In: MATTOSO, J. (Org.). História da vida privada em Portugal. Lisboa: Círculo de Leitores, Temas e Debates, 2011. p. 334-394.

MATA ZEFERINO, F. R. A. Anatômico jocoso, que em diversas operações manifesta a ruindade do corpo humano, para emenda do vicioso. Lisboa: Oficina do Doutor Manoel Alvarez Solano, 1755. v. II.

LOBO, F. R. Corte na aldeia. Introdução, notas e fixação do texto de José Adriano de Carvalho. Lisboa: Editorial Presença, 1992.

MCKENZIE, D. F. The book as an expressive form. In: MCKENZIE, D. F. Bibliography and the sociology of texts. Cambridge, UK: Cambridge University Press, 1999. p. 9-30.

MOISÉS, M. Dicionário de termos literários. São Paulo: Cultrix, 1974.

PÉCORA, A. À guisa do manifesto. In: PÉCORA, A. Máquina de gênero. São Paulo: Edusp, 2001. p. 3-15.

ROCHA, A. A epistolografia em Portugal. Lisboa: Temas portugueses, Imprensa Nacional, 1985.

RODRIGUES, G. A. Literatura e sociedade na obra de Frei Lucas de Santa Catarina (1600 - 1740). Lisboa: Casa da Moeda, 1983.

SILVA, I. F. Dicionário bibliográfico português. Lisboa: Imprensa Nacional: 1858. Tomo V.

VILLALTA, L. C. Censura literária e circulação de impressos entre Portugal e Brasil (1769-1821). In: DUTRA, E. F. MOLLIER, J. (org.). Política, nação e edição: o lugar dos impressos na construção da vida política no Brasil, Europa e Américas nos séculos XVIII-XX. São Paulo: Annablume, 2006. p. 111-134.

Recebido em 12/07/2019

Aceito em 20/08/2019

Publicado em 09/09/2019 